\title{
Suppressed Emotional Modulation on Early Auditory Processing of Predictable
}

\section{Stimuli}

Laura Ahumada ${ }^{1}$, Sergio Arthuro Mota-Rolim² ${ }^{2}$, Mario André Leocadio-Miguel ${ }^{1}$, John Fontenele Araujo ${ }^{1}$

${ }^{1}$ Physiology Department, Federal University of Rio Grande do Norte, Natal, Brazil; ${ }^{2}$ Brain Institute and Onofre Lopes University Hospital, Federal University of Rio Grande do Norte, Natal, Brazil.

\begin{abstract}
Author Note
We are grateful to Sergio Conde, Brian Sousa and Bruno Melo for their technical support with Matlab scripts. We also thank João Alencar for his advice on statistics. Laura Ahumada is thankful to the Conselho Nacional de Desenvolvimento Cientifico e Tecnologico (CNPq) for her Masters' scholarship and to the Conselho Nacional de Desenvolvimento Cientifico e Tecnologico, CNPq [484202/2013-8 and 458075/2014-0] for the research funding. We have no conflicts of interests to disclose.

Correspondence concerning this article should be addressed to Laura Ahumada, Physiology Department, Federal University of Rio Grande do Norte, Av. Salgado Filho, S/N, Natal, Brazil, 59078-970. E-mail: lauraahdz@gmail.com
\end{abstract}




\begin{abstract}
Emotion influences how we perceive the world, but the neural substrates of this modulation are not completely understood. Here, we aimed to evaluate how emotional state modulates the early sensory processing of auditory stimuli. We recorded auditory event-related potentials while participants were listening to neutral tones and watching emotional pictures simultaneously. To verify the emotional responses, we collected the subjective assessment of pictures, heart rate, and brain rhythms. We found that the emotional states failed in modulating N1 and P2 amplitudes. However, N1 amplitude decreased when we presented a picture, compared to a white background. These results suggest a suppressed emotional modulation over the processing of periodic neutral events, probably due to the predictability of these events. Nonetheless, we observed a deceleration of the heart rate during presentation of emotional pictures and an increase in theta power during the presentation of positive pictures, which confirms the induction of emotional reactions.
\end{abstract}

Keywords: Emotional States, Early Auditory Processing, ERP, Cross-modal Stimulation, Predictability. 


\section{Introduction}

Emotional experiences can change the way we perceive the world around us. This modulation may happen by increasing our focus on some specific details, or by strengthening the memory of specific events. For instance, emotional characteristics of images affects behavioral and physiological responses, which is interpreted as a sign of emotional processing (Lang et al., 1993, 1998). A classical way to study emotional modulation is by measuring changes in event-related potential (ERP), which are electrophysiological brain responses to specific stimuli, such as visual or auditory ones. It has been widely documented how pictures with positive and negative emotional valence modulate ERP. For instance, negative pictures generate a fast and prominent ERP in the frontal region, a brain area related to automatic attention (Cacioppo \& Gardner, 1999; Carretié et al., 2001, 2004). Additionally, when both negative and positive pictures are presented, a negative deflection over the cortical posterior area is generated in the first milliseconds, representing a selective encoding of affective images (Schupp et al., 2003b, 2003a). These results suggest that emotional-induced events probably catch more attentional resources due to their adaptive value (Nesse \& Ellsworth, 2009).

Nevertheless, when we witness a situation that triggers an emotional state, such as a car accident, the sensory information we receive from non-emotional sources, like a cellphone call, may be affected by this emotional state. In this case, a visual stimulus with 
affective features may modify the processing of an auditory non-emotional stimulus that appears at the same time, leading to a decreased or increased perception of auditory stimulus. Hypothetical situations like the previous one have been studied under laboratory conditions using cross-modal visual-auditory designs, in which emotional images are presented to evaluate their impact over the early sensory processing of auditory stimulus. In this case, auditory processing is measured using the amplitude of ERP's exogenous components, mainly N1 and P2 peaks. These early components have been associated to attentional processes because they reflect a response to the perceptual characteristic of external stimulus (Luck, 2005). The N1 peak is related to stimulus detection, while the less studied P2 might be involved in some aspects of the stimulus classification process (Crowley \& Colrain, 2004; Näätänen \& Picton, 1987).

During cross-modal visual-auditory stimulation, the effects of emotional pictures on auditory $\mathrm{N} 1$ and $\mathrm{P} 2$ amplitudes have been measured in both standard and deviant waveforms. In such paradigm it has been found that auditory N1 is not influenced by the emotional pictures in most of the studies (Gulotta et al., 2013; Pinheiro et al., 2017; Surakka et al., 1998). However, in Sugimoto et al. (2007), auditory N1, elicited by highly deviant tones, was larger when negative pictures were presented, and when it was elicited by standard tones auditory N1 was smaller during negative but not positive images displaying, suggesting that negative emotions direct attentional focus towards possible 
significant events (Sugimoto et al., 2007). The P2 component seems to be decreased when a standard tone is presented simultaneously with positive pictures (Sugimoto et al., 2007) or with positive and negative video clips (Gulotta et al., 2013), as an indicator of reduced attention to steady external events. However, in another study, it was observed an increase in the standard P2 during positive context, suggesting that positive situations facilitate the prediction of regular stimuli in the background (Pinheiro et al., 2017).

Despite the attempt to describe how emotion affects the processing of stimuli in a cross-modal setup, the above mentioned studies are inconsistent about the effect of visual emotional stimulation on the processing of innocuous sounds. Most of these studies did not evaluate the influence of emotional state elicited by grouped affective images over the auditory event, nor inquired how this emotional state modulates constant auditory background. (Gulotta et al., 2013; Pinheiro et al., 2017; Sugimoto et al., 2007; Surakka et al., 1998; Tartar et al., 2012).

Therefore, here we aimed to evaluate how emotional state elicited by affective pictures modulates the early sensory processing of periodic, neutral tones. We presented blocks of high arousal (with negative or positive valence) or neutral pictures, simultaneously with the exposure of neutral tones. To verify the emotional subjective and physiological responses, we measured both participants' self-report of pictures' emotional dimensions, and the heart rate response. Additionally, we measured the variability in the 
power spectra of brain oscillations (theta, alpha and beta bands) to investigate the participation of different cortical rhythms in emotional processing. We hypothesize that we will find significant differences in N1 and P2 amplitudes, as well as in heart rate response and brain rhythms, between neutral and affective conditions. Besides, we also hypothesize a correspondence of the subjective report of pictures' emotional dimensions with the standard values, which would confirm the effectiveness of emotional pictures to measure induced emotional reactions.

\section{Method}

\section{Participants}

Thirty-four participants (18 women, 16 men) volunteered into the study. They were all students, between 18 and 30 years old (Mean $=23.54, \mathrm{SD}=3.29)$, and with no visual or auditory impairment. The study was approved by the Ethics Committee of the Federal University of Rio Grande do Norte, Natal, Brazil (protocol number: 1.381.776) and all procedures were carried out according to the Declaration of Helsinki. Written informed consents were obtained from all volunteers before experimental procedures were initiated.

\section{Materials}

Emotional pictures and auditory stimulus. We selected 36 digital pictures from the International Affective Pictures System - IAPS (Lang, Bradley \& Cuthbert, 1997) and divided them evenly into three conditions: 1) negative valence and high arousal; 2) positive 
valence and high arousal; and 3) neutral valence ${ }^{1}$. We categorized these pictures based on the scores obtained in the Brazilian adaptation of the test (Lasaitis et al., 2008). We established an additional control condition, with a non-picture presentation, by presenting a white screen. Pictures were reproduced using SuperLab ${ }^{\circledR}$ (Cedrus Corporation) on a computer screen.

The auditory stimulus was a pure tone $(80 \mathrm{~dB}$ (SPL), 50ms, 200 samples per condition). We programmed the auditory stimulus using the Neuron-Spectrum-4/P system (NeuroSoft, Ivanovo, Russia) and presented it on both ears using inserted earphones (EARTONE Gold 3A, 3M).

Self-Assessment Manikin (SAM). SAM is an instrument used to assess the emotional dimensions of emotional stimuli such as the IAPS. This continuous scale consists of three parts that measure the pleasure, arousal, and dominance associated with an emotional reaction to an event (Bradley \& Lang, 1994). To address our aims, here we assessed only valence and arousal. Each of these parts contained a scale ranging from 1 to 9 points alongside five human figures expressing contrasting emotional reactions. The pleasure scale showed an unpleasant figure at the left (point 1) and a pleasant figure at the right end (point 9), while the arousal scale showed a calm figure at the left (point 1) and an

\footnotetext{
$\overline{1}$ The IAPS pictures selected for the study were: $1510,1640,1650,2215,2518,2710,3053,3063,3102,3170,3266$, $4680,4683,4800,5629,6260,6350,6571,7035,7100,7150,7175,7205,7211,7217,7235,7490,7491,8030,8185$ $8400,8490,8501,9050,9410,9921$.
} 
excited figure at the right end (point 9) of the scale. Participants used a keyboard to click on the number in the scale closer to the human figure that better represented their emotional reactions to the IAPS pictures showed on the computer screen.

\section{Procedure}

When participants arrived at the laboratory, they were informed about the purpose of the study. We performed the experiment in an isolated room and participants were seated in a comfortable chair located $92 \mathrm{~cm}$ away from a 23 inches LED screen of $1920 \mathrm{x}$ 1080 resolution, where visual stimuli were shown.

We presented the four conditions in separated blocks. The first condition (white screen) was always exhibited at the beginning, while the other three conditions of pictures (negatives, neutral and positive) were randomized between participants. Each block had a duration of 2 min. A working memory task (N-back) was presented during each intercondition interval, with a duration of $1 \mathrm{~min}$. The purpose of this task was to keep participants actively engaged in the experiment during the entire session. At the end of the experiment, each participant assessed the emotional properties of the pictures using the SAM scale.

EEG and ECG recording. Scalp electrodes were properly attached while participants were seated on the chair. Electroencephalogram (EEG) was recorded following the 10-20 International System indications on eight cortical channels (F3, F4, C3, C4, T3, 
T4, O1, O2) using the Neuron-Spectrum-4/P system (NeuroSoft, Ivanovo, Russia). We placed reference electrodes bilaterally on the mastoids, and ground electrode on the forehead. EEG was digitized with a $1000 \mathrm{~Hz}$ sampling rate $(0.5-100 \mathrm{~Hz}$ band pass $)$ and impedance was maintained below $7 \mathrm{k} \Omega$.

EEG signal was processed using Matlab toolbox EEGLAB 13.6.5b (Delorme \& Makeig, 2004). We applied a $30 \mathrm{~Hz}$ offline low pass filter and sinusoidal noise was removed by CleanLine plugin. We applied an independent component analysis (ICA) to remove eye blink artifacts. For auditory event-related potentials, epochs of $400 \mathrm{~ms}$ were extracted from the signal, a semi-automatic rejection algorithm was applied to reject epochs with noise (muscle artifacts or electrode drifts). At this point, we excluded two participants due to excess of artifacts. After EEG pre-processing, at least 160 epochs entered in the grand-averaging of ERP. We calculated N1 peak with a latency window between $50-150 \mathrm{~ms}$, and P2 peak with a latency window between $150-250 \mathrm{~ms}$. Regarding brain oscillations, we divided them into the following bands: a) theta $=4-7.75$ $\mathrm{Hz}$, b) alpha $=8-11.75 \mathrm{~Hz}, \mathrm{c})$ beta $1=15-17.75 \mathrm{~Hz}$, d) beta2 $=18-29.75 \mathrm{~Hz}$. We used 'pwelch' function in Matlab to calculate the power spectrum density of the EEG signal. Afterwards, the average power of each frequency band was extracted from all electrodes and conditions. 
We measured the electrocardiogram (ECG) using two electrodes located on the right mid-clavicle and lower left rib cage (Standard DII ECG derivation). We used NeuronSpectrum-4/P system (NeuroSoft, Ivanovo, Russia) for recording with a $1000 \mathrm{~Hz}$ sampling rate and a $0.5-100 \mathrm{~Hz}$ band-pass. Subsequently, the ECG signal was imported into Kubios HRV 2.2 (Tarvainen et al., 2014) to calculate the heart rate response. First, we corrected the epochs with artifacts using an automatic threshold correction provided by the software, but in some cases, epochs were rejected. The ECG signals of 4 participants were excluded due to excess of artifacts. After cleaning, we calculated the inter-beat intervals (R-R intervals).

Statistical analyses. We used the R Statistical Software (version 3.2.2, <www.rproject.org >) for the statistical analyses. Repeated-measures analyses of variance (ANOVAs) were conducted to compare the mean of the SAM score for valence and arousal and the mean of R-R intervals. A Pearson's correlation was conducted to test the relationship between the arousal report and the mean of R-R intervals. Auditory ERP and bands frequency power data were subjected to a Friedman non-parametric test, since they did not meet the assumption of normality. Friedman test and Nemenyi posthoc were implemented using the R package "PMCMR" (Pohlert, 2014). Additionally, we performed a factorial comparison for repeated measures to test hemispheric asymmetry using the $\mathrm{R}$ 
package "ARTool" (Kay \& Wobbrock, 2016) for non-parametric test. Alpha value for statistical significance was maintained below 0.05 .

\section{Results}

\section{Auditory ERP}

To create a graphic of the auditory ERP grand average we used a window of 300 ms. Friedman test comparison for the N1 component indicated an increase in its amplitude during the white screen viewing over the following electrodes: $\mathrm{C} 4\left(\mathrm{X}^{2}(3)=15.45 ; \mathrm{p}<0.01\right)$ and $\mathrm{C} 3\left(\mathrm{X}_{(3)}^{2}=7.76 ; \mathrm{p}<0.05\right)$; $44\left(\mathrm{X}_{(3)}^{2}=14.44 ; \mathrm{p}<0.01\right)$ and $\mathrm{T} 3\left(\mathrm{X}_{(3)}^{2}=9.49 ; \mathrm{p}<0.05\right)$; $\mathrm{O} 2\left(\mathrm{X}_{(3)}^{2}=28.28 ; \mathrm{p}<0.001\right)$ and $\mathrm{O} 1\left(\mathrm{X}_{(3)}^{2}=15.64 ; \mathrm{p}<0.001\right)$ (Figure 1). Nemenyi post hoc showed that these differences were significant at: a) $\mathrm{C} 4$ for white screen condition compared to negative $(\mathrm{p}<0.01)$, neutral $(\mathrm{p}<0.05)$ and positive conditions $(\mathrm{p}<0.05)$; $\mathrm{b})$ C3 between white screen and negative conditions $(\mathrm{p}<0.05)$; c) T4 between white screen and the other conditions $(\mathrm{p}<0.05)$; $)$ T3 between white screen and negative conditions ( $p$ $<0.05)$; e) $\mathrm{O} 2$ between white screen and the other conditions ( $<<0.001)$; and f) $\mathrm{O} 1$ for white screen compared to negative $(\mathrm{p}<0.05)$ and conditions $(\mathrm{p}<0.05)$. Besides, we found no significant differences between pictures conditions regarding the emotional content. Friedman test did not show any significant differences in the P2 peak between the conditions in most of the electrodes: $\mathrm{C} 4\left(\mathrm{X}^{2}(3)=4.46 ; \mathrm{p}>0.05\right)$ and $\mathrm{C} 3\left(\mathrm{X}^{2}(3)=2.81 ; \mathrm{p}>\right.$ $0.05) ; \mathrm{F} 4\left(\mathrm{X}_{(3)}=7.01 ; \mathrm{p}>0.05\right)$ and F3 $\left(\mathrm{X}^{2}(3)=3.86 ; \mathrm{p}>0.05\right) ; \mathrm{T} 4\left(\mathrm{X}^{2}(3)=6.64 ; \mathrm{p}>0.05\right)$ 
and T3 $\left(\mathrm{X}_{(3)}^{2}=1.16 ; \mathrm{p}>0.05\right) ; \mathrm{O} 2\left(\mathrm{X}_{(3)}^{2}=5.89 ; \mathrm{p}>0.05\right)$. Except for the result over the O1 electrode $\left(\mathrm{X}_{(3)}^{2}=8.14 ; \mathrm{p}<0.05\right)$. The post hoc analyses showed that the difference was specific between the white screen and the neutral condition $(p<0.05)$; although, in the visual inspection, it is possible to notice the absence of the P2 peak over the occipital electrodes (Figure 1). 
Figure 1

Grand average waveform of the Auditory ERP and topographic map of the N1 mean

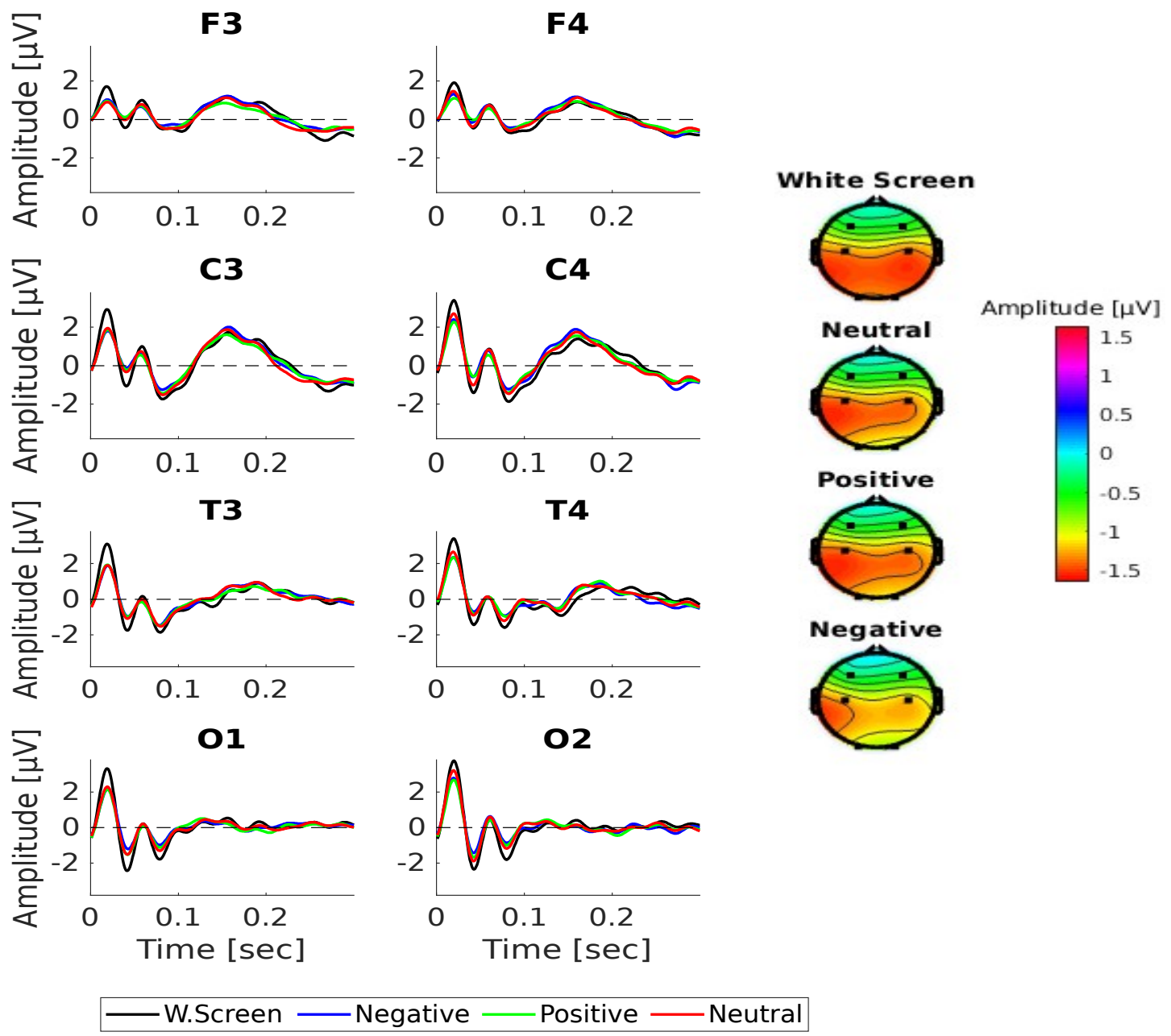


Note. Components amplitude were measured over the F3, F4, C3, C4, T3, T4, O1, and $\mathrm{O} 2$ electrodes and in the four conditions: white screen, negative, positive, and neutral. Results showed a reduction of N1 amplitude when an image is displayed.

\section{Self-reported assessment and heart rate response}

Results in SAM score showed that arousal was modulated by valence and was significantly different between the pictures categories $\left(\mathrm{F}_{(2,66)}=92.96 ; \mathrm{p}<0.001\right)$. Negative pictures $(\mathrm{M}=7.38, \mathrm{SD}=1.80)$ were assessed as significantly more arousing than positive $(\mathrm{M}=5.69, \mathrm{SD}=2.15)(\mathrm{p}<0.001)$ and neutral pictures $(\mathrm{M}=4.01, \mathrm{SD}=1.72)(\mathrm{p}<0.001)$. Additionally, positive pictures were significantly more arousing than neutral ones $(\mathrm{p}<$ 0.001). Valence scores were also different between the picture categories $\left(\mathrm{F}_{(2,66)}=459.82\right.$; $\mathrm{p}<0.001)$. Negative pictures $(\mathrm{M}=1.92, \mathrm{SD}=1.27)$ were judged as more aversive than neutral $(\mathrm{M}=5.37, \mathrm{SD}=1.10)(\mathrm{p}<0.001)$ and positive ones $(\mathrm{M}=6.77, \mathrm{SD}=1.73)(\mathrm{p}<$ $0.001)$; and positive pictures were judged as more pleasant than neutral ones $(\mathrm{p}<0.001)$.

The mean of R-R intervals showed a significant difference between the conditions $\left(\mathrm{F}_{(3,87)}=5.38 ; \mathrm{p}<0.01\right)$. Specifically, heart rate decreased as the mean of R-R intervals lengthened during the presentation of negative $(p<0.01)$ and positive pictures $(p<0.05)$ compared to the neutral ones (Figure 2). 
Figure 2

Mean (+/-SE) of R-R Interval in conditions with images

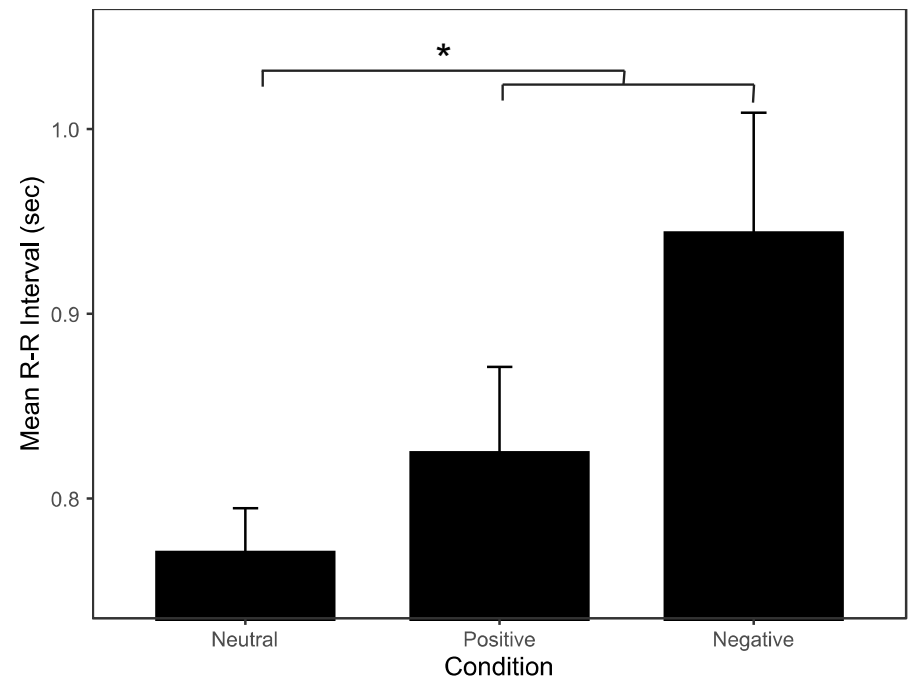

Note. R-R intervals increased in the positive and negative conditions. $(* \mathrm{p}<0.05)$.

We observed a positive correlation between the mean of the arousal report of positive pictures and the mean of R-R intervals in the positive condition $(r=0.42 ; \mathrm{p}<$ 0.05), and a positive correlation between the mean of the arousal report of negative pictures and the mean of $\mathrm{R}-\mathrm{R}$ intervals in the negative condition $(\mathrm{r}=0.41 ; \mathrm{p}<0.05)$ (Figure 3$)$. 
Figure 3

Correlation between the mean of $R-R$ Interval and the mean of the arousal scores

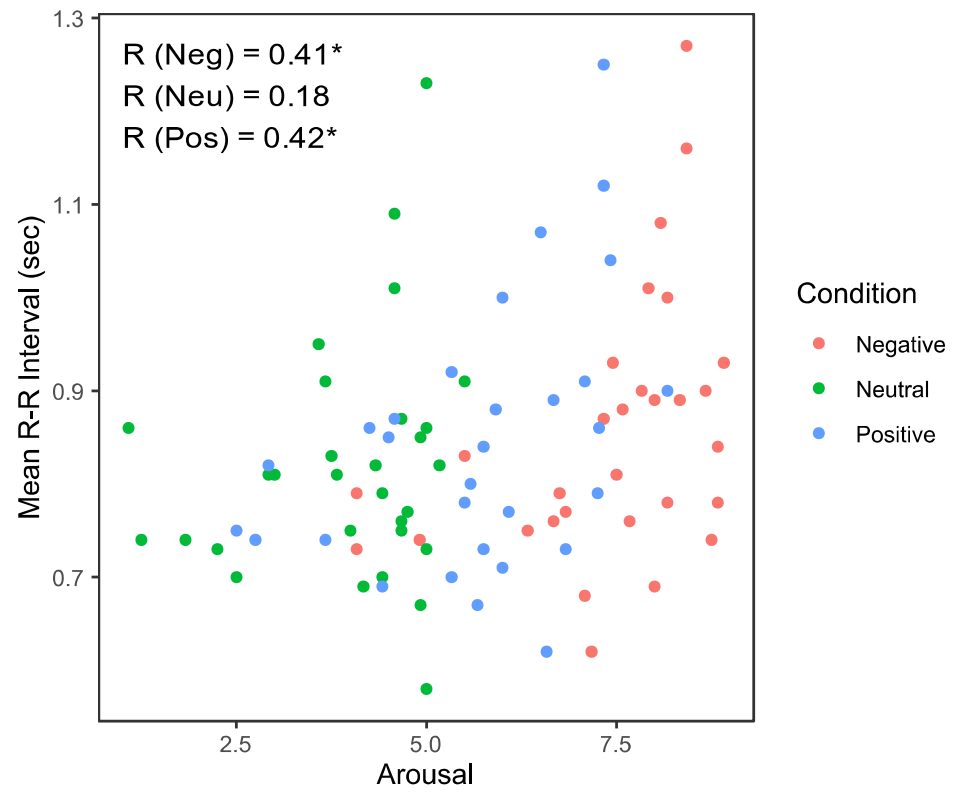

Note. Correlations were performed in the conditions with images. We observed a positive correlation between R-R intervals and the arousal score in the positive and negative conditions. $\left({ }^{*} \mathrm{p}<0.05\right)$.

\section{Brain oscillations}

In the spectral analyses, we observed a significant difference in alpha $(8-11.75 \mathrm{~Hz})$ power over $\mathrm{O} 2\left(\mathrm{X}_{(3)}^{2}=17.4 ; \mathrm{p}<0.001\right)$ and $\mathrm{O} 1\left(\mathrm{X}_{(3)}^{2}=17.25 ; \mathrm{p}<0.001\right)$ electrodes. Specifically, there was a decrease in alpha power during negative $(\mathrm{O} 2: \mathrm{p}<0.001 ; \mathrm{O} 1: \mathrm{p}<$ $0.001)$ and positive $(\mathrm{O} 2: \mathrm{p}<0.05 ; \mathrm{O} 1: \mathrm{p}<0.01)$ pictures presentation compared to the white screen condition, in both occipital electrodes. We also observed a decrease in alpha 
power during the presentation of negative pictures $(\mathrm{p}<0.05)$ compared to the neutral picture presentation. In theta $(4-7.75 \mathrm{~Hz})$ power, the opposite effect was found over the same locations: $\mathrm{O} 2\left(\mathrm{X}_{(3)}^{2}=16.24 ; \mathrm{p}<0.001\right)$ and $\mathrm{O} 1\left(\mathrm{X}_{(3)}^{2}=16.8 ; \mathrm{p}<0.001\right)$ electrodes. We observed an increase of theta power during pictures presentation (negative: $\mathrm{p}<0.05$; neutral: $\mathrm{p}<0.05$; positive: $\mathrm{p}<0.001)$ over $\mathrm{O} 2$ electrode in comparison with the white screen presentation, and during neutral $(\mathrm{p}<0.001)$ and positive $(\mathrm{p}<0.01)$ pictures presentation over $\mathrm{O} 1$ electrode, in comparison to the white screen presentation (Figure 4).

\section{Figure 4}

Boxplot values of alpha and theta bands power

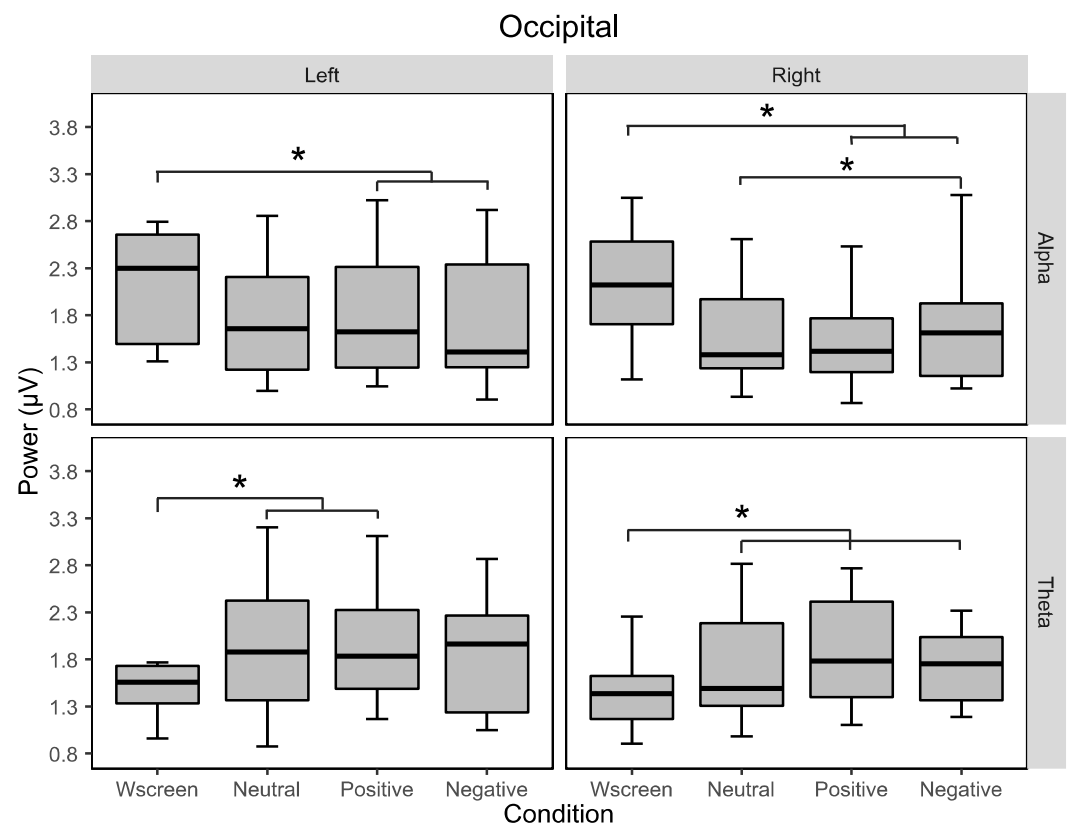


Note. Values were calculated in all conditions (white screen, neutral, positive, and negative) over the left and right occipital electrodes. Results showed a decrement in alpha power and an increment in theta power when an image is displayed. $(* \mathrm{p}<0,05)$.

Further analyses in theta band (Figure 5) revealed an increment in its power during the presentation of positive images $\left(\mathrm{F} 4: \mathrm{X}^{2}{ }_{(3)}=9.49 ; \mathrm{p}<0.05 / \mathrm{T} 4: \mathrm{X}^{2}{ }_{(3)}=13.31 ; \mathrm{p}<0.01\right)$ compared to neutral images over the F4 electrode $(\mathrm{p}<0.05)$ and neutral images and the white screen condition over the $\mathrm{T} 4$ electrode $(\mathrm{p}<0.05)$. We observed no significant differences in beta1 and beta2 bands ( $15-17.75 \mathrm{~Hz}$ and $18-29.75 \mathrm{~Hz}$, respectively).

\section{Figure 5}

Boxplot values of theta power

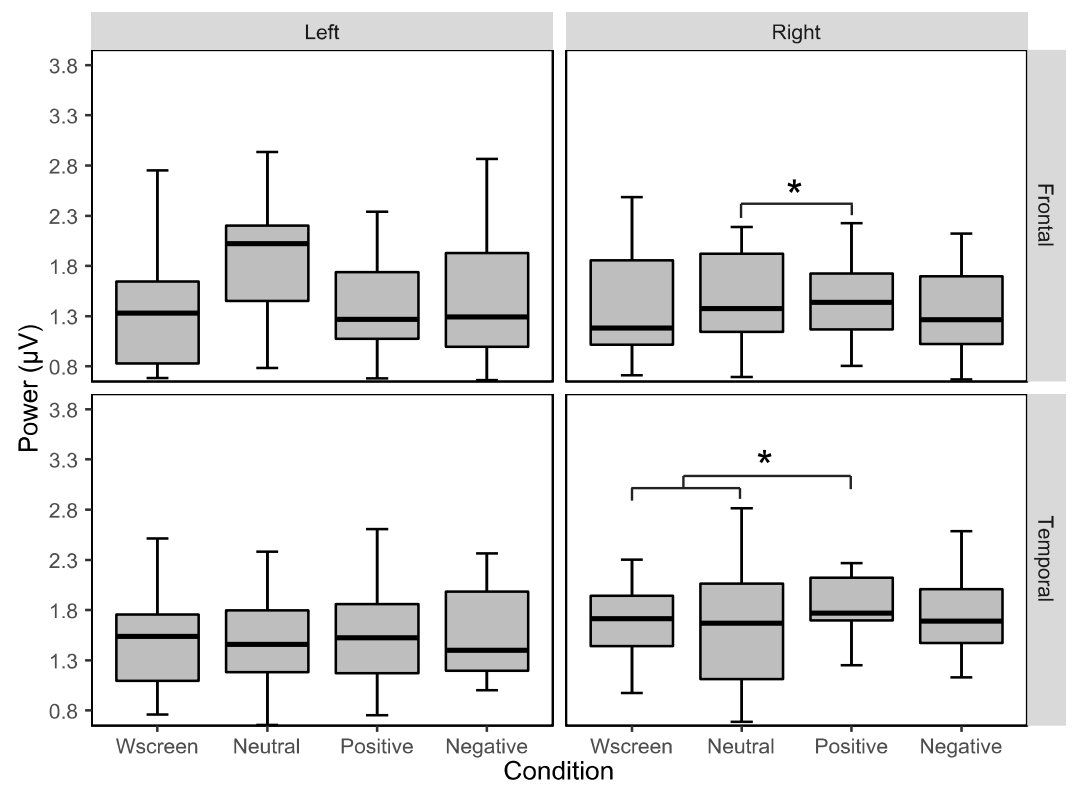


Note. Values were calculated in all conditions (white screen, neutral, positive, and negative) over frontal left, frontal right, temporal left, and temporal right electrodes. We observed an increment in theta power at right sites during the positive condition. $\left({ }^{*} \mathrm{p}<0,05\right)$.

\section{Discussion}

Emotional events in our daily life permeate the way we perceive the world. The goal of this study was to evaluate how emotional state modulates the processing of a neutral sound. Our results showed that emotional pictures affected neither N1, nor P2 amplitude, suggesting that predictability of the auditory stimuli may prevent subjects from relocating attention towards tones, even when they were surrounded by an emotional context, causing a suppression of the emotional modulation. Nevertheless, the subjective assessment of pictures, heart rate deceleration, and activity in frontal and temporal theta band confirmed that pictures elicited affective responses in participants.

\section{Auditory ERP}

We observed no emotional effect of the pictures on the N1 auditory peak. Instead, we found a decrease of N1 amplitude when participants were watching any picture. In all conditions, participants were exposed to visual stimulation at the same time they were listening to a periodic tone. However, during the white screen viewing, the stimulus' composition was less visually complex in comparison with the other three conditions, which means that pictures conditions had a high perceptual load. It was previously reported that increasing perceptual load in a visual task might result in reduced auditory ERP to 
irrelevant stimuli (Molloy et al., 2015). This phenomenon is related to the limited capacity of attentional resources in our Nervous System, which seems to act as an adaptive strategy to protect from distraction (Lavie, 2005; Simon et al., 2016). As it was reported before, N1 amplitude can be modulated by attention (Schwent et al., 1976; Woldorff \& Hillyard, 1991). In our study, an enhancement of visual stimuli complexity, introduced by the images, increased the perceptual load, which leads to the apprehension of more attentional resources, even in the absence of a cognitive task, and consequently resulted in an attenuation of the auditory N1.

Besides, we also observed that the auditory $\mathrm{P} 2$ component was very similar among the four conditions. This result is not in accordance with other findings in which P2 is attenuated during viewing of positive and negative video clips (Gulotta et al., 2013), during viewing of positive slides (Sugimoto et al., 2007), or enhanced in the presence of positive context (Pinheiro et al., 2017). This disagreement may be due to methodological differences among these studies, such as the presentation of the pictures in blocks and tones' features. Another possible explanation regarding the difference in the auditory ERP is that although the cortical generators of the $\mathrm{N} 1$ and $\mathrm{P} 2$ components are anatomically closer (Shahin et al., 2007), these components may represent different processes (Crowley \& Colrain, 2004). Therefore, the features that affect N1 amplitude do not necessarily exert 
any change in P2 amplitude. More research on P2 is clearly warranted, since its functional role is not well understood (Crowley \& Colrain, 2004; Sugimoto et al., 2007).

The suppression of emotional modulation on the auditory ERP could reflect the absence of a connection between pictures and tones. Thus, tones could be irrelevant to the processing of emotions. The experimental design is another factor that could have influenced our results since we used a passive observation experiment, in which the auditory stimulation was the same throughout the experiment. Classical cross-modal studies present an oddball design, where frequent and infrequent sounds are presented simultaneously or before the visual stimuli, during a passive or active observation experiment (Gulotta et al., 2013; Pinheiro et al., 2017; Sugimoto et al., 2007; Surakka et al., 1998; Tartar et al., 2012). The absence of variation in the auditory stimulus may either lead to a habituation in the early components (Rosburg et al., 2006; Woods \& Elmasian, 1986) or prevent a significant neural response as a result of predictability (see more in Alho et al., 1992; Sussman et al., 2003).

We believe the last hypothesis seems more appropriate because habituation happens after the first trials, which means that components amplitude decreases after the first stimuli; however they do not disappear (Rosburg et al., 2006). Predictability, on the other hand, inhibits the attentional capture by irrelevant stimuli. When an unexpected event appears while we are involved in a relevant task, our nervous system involuntary relocates 
attention due to a potentially significant event (Sussman et al., 2003). However, when we can predict the occurrence of an irrelevant event, the attentional relocation may be suppressed (Sussman et al., 2003; Volosin \& Horváth, 2014). In our study, auditory events were stable and, thus, participants could unconsciously predict their appearance, without attentional processing (Bendixen et al., 2012). Besides, these expected tones did not carry any important information. Considering this evidence, we may assume that emotion did not affect the way the auditory stimuli were processing due to their predictability, thus attentional resources were kept for the processing of images. If there is no variation in the environment, emotional modulation over background stimuli will be suppressed.

\section{Self-reported assessment and heart rate response}

Assessment of the pictures' emotional dimensions and the heart rate response confirmed that the instrument we used to induce emotional responses was suitable. Correlation between the values of emotional pictures arousal and the mean of the R-R intervals reinforces the previous argument, as it was mentioned before by Choi et al., (2017). Furthermore, the observed deceleration of the heart rate has been related with cortical activation and attentional disposition to affective events (Graham \& Clifton, 1966; Palomba et al., 1997; Pollatos et al., 2007). Therefore, our results suggest that visual emotional stimulation prompts affective responses at peripheral and central levels of the nervous system. 


\section{Brain oscillations}

Alpha oscillation increases during a relaxed waking state with eyes closed (Adrian $\&$ Matthews, 1934) and decreases during visual stimulation (Mazaheri \& Picton, 2005; Pfurtscheller \& Lopes, 1999; Pfurtscheller et al., 1994). In our results, we observed a prominent decreasing of alpha power when participants were presented with pictures, but not when they were watching a white screen, which suggests the presence of a sensory processing response (Pfurtscheller \& Lopes, 1999). Increased power in theta band at occipital sites is likely a consequence of decreasing alpha power. These findings complement the result we found in the $\mathrm{N} 1$ component, in the sense that sensory processing of highly complex visual stimuli recruited more attentional resources.

Interestingly, we found that theta band power increased during the positive condition over the frontal and temporal regions in the right hemisphere. This is consistent with previous findings (Aftanas et al., 2001, 2004; Balconi \& Lucchiari, 2006). As proposed by Aftanas et al. (2004) this response reflects an evaluation of the affective significance of stimulus. Thereby, regardless of the lack of emotional effect on the auditory processing, the emotional stimulation used in this experiment modified the brain responses at the level of neural oscillations. Furthermore, theta band activity was significantly different between the conditions only over the electrodes at the right side. Such activity 
may reflect a hemispheric asymmetry in the discrimination of the stimuli affective significance (Aftanas et al., 2002).

In our experimental design, we presented the affective pictures in blocks because we wanted to reproduce an emotional state, this could represent a disadvantage since the tones and the pictures might not have been correctly matched. Moreover, although these pictures are good to generate emotional responses, it is possible that they are not strong enough to modulate background of non-emotional information in a cross-modal design. For future research, we recommend to consider the effect of predictability in the experimental design.

\section{Conclusion}

Our findings suggest that an emotional situation does not interfere with the ordinary processing of other neutral environmental stimuli when these events are repetitive and do not represent an essential source of information. Nonetheless, we can evidence the emotional influence over the participants' subjective, autonomic and central responses through the pictures assessment, the cardiac response and the activation of brain oscillations, respectively - thus we can confirm the IAPS efficacy to generate emotional reactions. An emotional experience may direct our attention towards an ordinary event, as long as this event represents a potential source of relevant information. 


\section{References}

Adrian, E. D., \& Matthews, B. H. (1934). The interpretation of potential waves in the cortex. The Journal of Physiology, 81(4), 440-471.

https://doi.org/10.1113/jphysiol.1934.sp003147

Aftanas, L. I., Reva, N. V., Varlamov, A. A., Pavlov, S. V., \& Makhnev, V. P. (2004). Analysis of evoked EEG synchronization and desynchronization in conditions of emotional activation in humans: Temporal and topographic characteristics. Neuroscience and Behavioral Physiology, 34(8), 859-867. https://doi.org/10.1023/B:NEAB.0000038139.39812.eb

Aftanas, L. I., Varlamov, A. A., Pavlov, S. V., Makhnev, V. P., \& Reva, N. V. (2001). Affective picture processing: Event-related synchronization within individually defined human theta band is modulated by valence dimension. Neuroscience Letters, 303(2), 115-118. https://doi.org/10.1016/S0304-3940(01)01703-7

Aftanas, Ljubomir I., Varlamov, A. A., Pavlov, S. V., Makhnev, V. P., \& Reva, N. V. (2002). Time-dependent cortical asymmetries induced by emotional arousal: EEG analysis of event-related synchronization and desynchronization in individually defined frequency bands. International Journal of Psychophysiology, 44(1), 67-82. https://doi.org/10.1016/S0167-8760(01)00194-5 
Alho, K., Woods, D. L., Algazl, A., \& Naatanen, R. (1992). Intermodal selective attention . II . Effects of attentional load on processing of auditory and visual stimuli in central space. Electroencephalography and Clinical Neurophysiology, 82, 356-368. https://doi.org/https://doi.org/10.1016/0013-4694(92)90005-3

Balconi, M., \& Lucchiari, C. (2006). EEG correlates (event-related desynchronization) of emotional face elaboration: A temporal analysis. Neuroscience Letters, 392(1-2), 118-123. https://doi.org/10.1016/j.neulet.2005.09.004

Bendixen, A., SanMiguel, I., \& Schröger, E. (2012). Early electrophysiological indicators for predictive processing in audition: A review. International Journal of Psychophysiology, 83(2), 120-131. https://doi.org/10.1016/j.ijpsycho.2011.08.003

Bradley, M., \& Lang, P. J. (1994). Measuring Emotion: The Self-Assessment Semantic Differential Manikin and the. Journal of Behavior Therapy and Experimental Psychiatry, 25(I), 49-59. https://doi.org/10.1016/0005-7916(94)90063-9

Cacioppo, J. T., \& Gardner, W. L. (1999). EMOTION. Annual Review of Psychology, 50(1), 191-214. https://doi.org/10.1146/annurev.psych.50.1.191

Carretié, L., Hinojosa, J. A., Martín-Loeches, M., Mercado, F., \& Tapia, M. (2004). Automatic attention to emotional stimuli: Neural correlates. Human Brain Mapping, 22(4), 290-299. https://doi.org/10.1002/hbm.20037 
Carretié, L., Mercado, F., Tapia, M., \& Hinojosa, J. A. (2001). Emotion, attention, and the "negativity bias", studied through event-related potentials. International Journal of Psychophysiology, 4l(1), 75-85. https://doi.org/10.1016/S0167-8760(00)00195-1

Choi, K. H., Kim, J., Kwon, O. S., Kim, M. J., Ryu, Y. H., \& Park, J. E. (2017). Is heart rate variability (HRV) an adequate tool for evaluating human emotions? - A focus on the use of the International Affective Picture System (IAPS). Psychiatry Research, 251, 192-196. https://doi.org/10.1016/j.psychres.2017.02.025

Crowley, K. E., \& Colrain, I. M. (2004). A review of the evidence for P2 being an independent component process: Age, sleep and modality. Clinical Neurophysiology, 115(4), 732-744. https://doi.org/10.1016/j.clinph.2003.11.021

Delorme, A., \& Makeig, S. (2004). EEGLAB: an open source toolbox for analysis of single-trial EEG dynamics including independent component analysis. Journal of neuroscience methods, 134(1), 9-21. https://doi.org/10.1016/j.jneumeth.2003.10.009

Graham, F. K., \& Clifton, R. K. (1966). Heart-rate change as a component of the orienting response. Psychological Bulletin, 65(5), 305-320. https://doi.org/10.1037/h0031048

Gulotta, B., Sadia, G., \& Sussman, E. (2013). Emotional processing modulates attentional capture of irrelevant sound input in adolescents. International Journal of Psychophysiology, 88(1), 40-46. https://doi.org/10.1016/j.jpsycho.2013.01.003 
Kay, M., \& Wobbrock, J. (2016). ARTool: aligned rank transform for nonparametric factorial ANOVAs. $R$ package version 0.10, 2. https://doi.org/10.1145/1978942.1978963 https://doi.org/10.5281/zenodo.2556415

Lang, P. J., Bradley, M. M., \& Cuthbert, B. N. (1997). International Affective Picture System (IAPS): Technical Manual and Affective Ratings. NIMH Center for the Study of Emotion and Attention, 1, 39-58.

Lang, P. J., Bradley, M. M., \& Cuthbert, B. N. (1998). Emotion, motivation, and anxiety: Brain mechanisms and psychophysiology. Biological Psychiatry, 44(12), 1248-1263. https://doi.org/10.1016/S0006-3223(98)00275-3

Lang, P. J., Greenwald, M. K., Bradley, M. M., \& Hamm, A. O. (1993). Looking at pictures: affective, facial, visceral, and behavioral reactions. Psychophysiology, 30(3), 261-273. http://www.ncbi.nlm.nih.gov/pubmed/8497555

Lavie, N. (2005). Distracted and confused?: Selective attention under load. Trends in Cognitive Sciences, 9(2), 75-82. https://doi.org/10.1016/j.tics.2004.12.004

Luck, S. J. (2005). An introduction to the event-related potential technique. In MIT Press. http://doi.wiley.com/10.1118/1.4736938 
Mazaheri, A., \& Picton, T. W. (2005). EEG spectral dynamics during discrimination of auditory and visual targets. Cognitive Brain Research, 24(1), 81-96. https://doi.org/10.1016/j.cogbrainres.2004.12.013

Molloy, K., Griffiths, T. D., Chait, M., \& Lavie, N. (2015). Inattentional Deafness: Visual Load Leads to Time-Specific Suppression of Auditory Evoked Responses. Journal of Neuroscience, 35(49), 16046-16054. https://doi.org/10.1523/JNEUROSCI.293115.2015

Näätänen, R., \& Picton, T. (1987). The N1 wave of the human electric and magnetic response to sound: a review and an analysis of the component structure. Psychophysiology, 24 (4), 97-113. https://doi.org/10.1111/j.14698986.1987.tb00311.x

Nesse, R. M., \& Ellsworth, P. C. (2009). Evolution, emotions, and emotional disorders. American Psychologist, 64(2), 129-139. https://doi.org/10.1037/a0013503

Palomba, D., Angrilli, a, \& Mini, a. (1997). Visual evoked potentials, heart rate responses and memory to emotional pictorial stimuli. International Journal of Psychophysiology, 27(1), 55-67. https://doi.org/10.1016/S0167-8760(97)00751-4 
Pfurtscheller, G, \& Lopes, F. H. (1999). Event-related EEG / MEG synchronization and desynchronization : basic principles. Clinical Neurophysiology, 110, 1842-1857. https://doi.org/10.1016/S1388-2457(99)00141-8

Pfurtscheller, Gert, Neuper, C., \& Mohl, W. (1994). Event-related desynchronization (ERD) during visual processing. International Journal of Psychophysiology, 16(2-3), 147-153. https://doi.org/10.1016/0167-8760(89)90041-X

Pinheiro, A. P., Barros, C., Dias, M., \& Niznikiewicz, M. (2017). Does emotion change auditory prediction and deviance detection? Biological Psychology, 127, 123-133. https://doi.org/10.1016/j.biopsycho.2017.05.007

Pohlert, T. (2014). The Pairwise Multiple Comparison of Mean Ranks Package (PMCMR). R Package. https://doi.org/http://cran.ms.unimelb.edu.au/web/packages/PMCMR/vignettes/ PMCMR.pdf

Pollatos, O., Herbert, B. M., Matthias, E., \& Schandry, R. (2007). Heart rate response after emotional picture presentation is modulated by interoceptive awareness. International Journal of Psychophysiology, 63(1), 117-124.

https://doi.org/10.1016/j.ijpsycho.2006.09.003 
Lasaitis, C., Ribeiro, R. L., Freire, M. V., \& Bueno, O. F. A. (2008). Atualização das normas brasileiras para o International Affective Picture System (IAPS). Revista de Psiquiatria Do Rio Grande Do Sul, 30(3), 230-235. https://doi.org/10.1590/s010181082008000400012

Rosburg, T., Trautner, P., Boutros, N. N., Korzyukov, O. A., Schaller, C., \& Elger, E. (2006). Habituation of auditory evoked potentials in intracranial and extracranial recordings. 43, 137-144. https://doi.org/10.1111/j.1469-8986.2006.00391.x

Schupp, H. T., Junghöfer, M., Weike, A. I., \& Hamm, A. O. (2003a). Attention and emotion: an ERP analysis of facilitated emotional stimulus processing. Neuroreport, 14(8), 1107-1110. https://doi.org/10.1097/00001756-200306110-00002

Schupp, H. T., Junghöfer, M., Weike, A. I., \& Hamm, A. O. (2003b). Emotional facilitation of sensory processing in the visual cortex. Psychological Science: A Journal of the American Psychological Society / APS, 14(1), 7-13. https://doi.org/10.1111/1467-9280.01411

Schwent, V. L., Hillyard, S. A., \& Galambos, R. (1976). Selective attention and the auditory vertex potential. II. Effects of signal intensity and masking noise. Electroencephalography and Clinical Neurophysiology, 40(6), 615-622. https://doi.org/10.1016/0013-4694(76)90136-X 
Shahin, A. J., Roberts, L. E., Miller, L. M., McDonald, K. L., \& Alain, C. (2007). Sensitivity of EEG and MEG to the N1 and P2 auditory evoked responses modulated by spectral complexity of sounds. Brain Topography, 20(2), 55-61. https://doi.org/10.1007/s10548-007-0031-4

Simon, S. S., Tusch, E. S., Holcomb, P. J., \& Daffner, K. R. (2016). Increasing working memory load reduces processing of cross-modal task-irrelevant stimuli even after controlling for task difficulty and executive capacity. Frontiers in Human Neuroscience, 10, 1-13. https://doi.org/10.3389/fnhum.2016.00380

Sugimoto, S., Nittono, H., \& Hori, T. (2007). Visual emotional context modulates brain potentials elicited by unattended tones. International Journal of Psychophysiology, 66(1), 1-9. https://doi.org/10.1016/j.ijpsycho.2007.05.007

Surakka, V., Tenhunen-Eskelinen, M., Hietanen, J. K., \& Sams, M. (1998). Modulation of human auditory information processing by emotional visual stimuli. Brain Research. Cognitive Brain Research, 7(2), 159-163. https://doi.org/10.1016/S09266410(98)00021-4

Sussman, E., Winkler, I., \& Schröger, E. (2003). Top-down control over involuntary attention switching in the auditory modality. Psychonomic Bulletin \& Review, 10(3), 630-637. https://doi.org/10.3758/BF03196525 
Tartar, J. L., de Almeida, K., McIntosh, R. C., Rosselli, M., \& Nash, A. J. (2012).

Emotionally negative pictures increase attention to a subsequent auditory stimulus.

International Journal of Psychophysiology, 83(1), 36-44.

https://doi.org/10.1016/j.ijpsycho.2011.09.020

Tarvainen, M. P., Niskanen, J. P., Lipponen, J. A., Ranta-aho, P. O., \& Karjalainen, P. A. (2014). Kubios HRV - Heart rate variability analysis software. Computer Methods and Programs in Biomedicine, 113(1), 210-220.

https://doi.org/10.1016/j.cmpb.2013.07.024

Volosin, M., \& Horváth, J. (2014). Knowledge of sequence structure prevents auditory distraction: An ERP study. International Journal of Psychophysiology, 92(3), 93-98. https://doi.org/10.1016/j.ijpsycho.2014.03.003

Woldorff, M. G., \& Hillyard, S. A. (1991). Modulation of early auditory processing during selective listening to rapidly presented tones. Electroencephalography and Clinical Neurophysiology, 79(3), 170-191. https://doi.org/10.1016/0013-4694(91)90136-R

Woods, D. L., \& Elmasian, R. (1986). The habituation of event-related potentials to speech sounds and tones. Electroencephalography and Clinical Neurophysiology, 65, 447459. https://doi.org/https://doi.org/10.1016/0168-5597(86)90024-9 